Pesq. Vet. Bras. 35(3):281-290, março 2015 DOI: $10.1590 / \mathrm{S} 0100-736 \mathrm{X} 2015000300012$

\title{
Avaliação do perfil metabólico de vacas da raça Holandesa durante o período de transição ${ }^{1}$
}

\begin{abstract}
Emerson A. Alvarenga ${ }^{2 *}$, Gustavo H.F.A. Moreira², Elias J. Facury Filho², Fabíola O.P. Leme $^{2}$, Sandra G. Coelho ${ }^{3}$, Lívio R. Molina ${ }^{2}$, Juliana A.M. Lima ${ }^{3}$ e Antônio U. Carvalho ${ }^{2}$

ABSTRACT.- Alvarenga E.A., Moreira G.H.F.A., Facury Filho E.J., Leme F.O.P., Coelho S.G., Molina L.R., Lima J.A.M. \& Carvalho A.U. 2015. [Evaluation of the metabolic profile of Holstein cows during the transition period.] Avaliação do perfil metabólico de vacas da raça Holandesa durante o período de transição. Pesquisa Veterinária Brasileira 35(3):281290. Departamento de Clínica e Cirurgia Veterinárias, Escola de Veterinária, Universidade Federal de Minas Gerais, Av. Antônio Carlos 6627, Cx. Postal 567, Campus Pampulha, Belo Horizonte, MG 30123-970, Brazil. E-mail: alvarenga.ea@gmail.com

The transition period is a time of great challenge for dairy cows, since most metabolic problems occur at this time and can compromise the entire lactation, resulting in a significant economic loss to commercial farms. This study evaluated the metabolic profile of dairy cows during the transition period. Twelve Holstein cows between three weeks pre-calving until three weeks postpartum was used in this study. They remained in a free-stall system, located in Inhaúma, Minas Gerais, during October to December 2012. The metabolic profile were composed by non-esterified fatty acids (NEFA), beta-hydroxybutyrate (BHBA), cholesterol (COLES), total protein (TP), albumin (ALB), calcium, phosphorus, magnesium as well as the activity serum enzymes aspartate transaminase (AST) and lactate dehydrogenase (LDH). There were differences in serum NEFA and BHBA between prepartum and postpartum $(\mathrm{p}<0.05)$. Observed a decrease in the concentration of COLES with the approaching birth with subsequent increase $(\mathrm{p}<0.05)$. Serum concentrations of minerals, PT and ALB did not differ ( $p>0.05)$. The enzymatic activity of AST and LDH were higher in the postpartum period $(\mathrm{p}<0.05)$. The evaluation of the metabolic profile is an important monitoring tool. Changes in the metabolic profile of cows during the transition period are motivated by energetic changing. Cows that were evaluated have a small risk of developing postpartum diseases related to the transition period.
\end{abstract}

INDEX TERMS: Ketosis, monitoring, diagnosis, transition period, dairy cows.

RESUMO.- 0 período de transição é um momento de grande desafio para vacas de aptidão leiteira, uma vez que, a maioria dos problemas metabólicos ocorre nesta fase podendo prejudicar toda a expectativa de produção durante a lactação, resultando em impacto econômico significativo para fazendas de produção de leite. Este trabalho teve como objetivo avaliar o perfil metabólico de vacas da raça

\footnotetext{
${ }^{1}$ Recebido em 12 de junho de 2014.

Aceito para publicação em 13 de janeiro de 2015.

${ }^{2}$ Departamento de Clínica e Cirurgia Veterinárias, Escola de Veterinária, Universidade Federal de Minas Gerais (UFMG), Av. Antônio Carlos 6627, Cx. Postal 567, Campus Pampulha, Belo Horizonte, MG 30123-970, Brasil. *Autor para correspondência: alvarenga.ea@gmail.com

${ }^{3}$ Departamento de Zootecnia, Escola de Veterinária, UFMG, Av. Antônio Carlos 6627, Cx. Postal 567, Campus Pampulha, Belo Horizonte, MG 30123-970.
}

Holandesa durante o período de transição. Doze vacas Holandesas foram avaliadas, três semanas pré-parto até três semanas pós-parto, em sistema free-stall, localizado em Inhaúma, Minas Gerais, no período de outubro a dezembro de 2012. Avaliou-se o perfil metabólico através da concentração sérica de ácidos graxos não esterificados (AGNE), beta hidroxibutirato (BHBA), colesterol (COLES), proteína total (PT), albumina (ALB), cálcio, fósforo, magnésio bem como a atividade sérica das enzimas aspartato transaminase (AST) e lactato desidrogenase (LDH). As concentrações séricas de AGNE e BHBA foram diferentes entre o pré-parto e pós-parto $(p<0,05)$. Observou-se diminuição na concentração de COLES com a aproximação do parto com posterior aumento $(\mathrm{p}<0,05)$. As concentrações séricas dos minerais, PT e ALB não apresentaram diferenças $(p>0,05)$ no período avaliado. A atividade enzimática de AST e LDH 
foram maiores no período pós-parto $(\mathrm{p}<0,05)$. A avaliação do perfil metabólico é uma importante ferramenta de monitoramento e, na situação estudada, demonstrou alterações do perfil energético das vacas entre os períodos pré e pós-parto, relacionadas provavelmente a diminuição da ingestão de alimentos. A luz dos resultados do perfil metabólico, o rebanho avaliado possui pequeno risco para a ocorrência de enfermidades no pós-parto relacionadas ao período de transição.

TERMOS DE INDEXAÇÃO: Cetose, monitoramento, diagnóstico, período de transição, gado de leite.

\section{INTRODUÇÃO}

0 período de transição é um momento de grande desafio para vacas de aptidão leiteira (Drackley et al. 2005). A maioria dos problemas metabólicos ocorre nesta fase e podem prejudicar toda a expectativa de produção durante a lactação (Dann et al. 1999, Drackley 1999), resultando em impacto econômico significativo para fazendas de produção de leite (Burhans et al. 2003).

As alterações que ocorrem no organismo animal durante o período de transição são adaptativas e tem o intuito de preparar a vaca para o final da gestação e o início da lactação (Wittiwer 2000b, Roche 2009). O metabolismo energético é influenciado pelas alterações endócrinas, pela diminuição no consumo de alimentos e maior demanda por nutrientes, o que induz a mobilização de tecido adiposo (Grum et al. 1996, Drackley 1999). 0 déficit energético entre a energia ingerida através dos alimentos e a energia utilizada pelo organismo para mantença e produção caracteriza o balanço energético negativo (BEN) (Baumgard et al. 2006).

O fígado é o órgão responsável pela identificação de necessidades nutricionais de todos os tecidos do organismo e atua ajustando o seu metabolismo para atender a demanda (Seifter \& Englard 1994, Drackley et al. 2005). A ocorrência de uma lesão tecidual ou mudanças no metabolismo hepático acarretarão modificação nos componentes dos fluidos circulantes (Stockham \& Scott 2008). 0 aumento da atividade de enzimas hepáticas, como aspartato aminotransferase (AST) e lactato desidrogenase (LDH), pode ser utilizado como indicador destas alterações (Kaneko et al. 2008).

0 metabolismo proteico pode ser influenciado por diversos fatores como a nutrição, o processo do parto e a lactação, além das estações do ano e de doenças concomitantes (Contreras 2000), sendo as proteínas totais e a albumina, indicadores deste metabolismo. Os minerais apresentam alterações em suas concentrações sanguíneas durante o período de transição (Goff 2006). A crescente demanda nutricional no final de gestação, a produção de colostro e a queda acentuada da ingestão de matéria seca (Bell 1995, Grummer 1995, Drackley 1999) fazem com que, muitas vezes, as concentrações séricas dos minerais estejam abaixo das concentrações fisiológicas (Goff 2006), levando os animais a apresentarem hipocalcemia, hipofosfatemia e hipomagnesemia (Goff 2008, Duffield \& LeBlanc 2009, Goff 2009).

A implementação de programas de monitoramento de saúde do rebanho visa detectar os problemas precocemente a fim de imediata intervenção ou acompanhamento da situação (Oetzel \& McGuirk 2007, LeBlanc 2010, Oetzel 2010). A análise do perfil metabólico permite avaliar a condição energética, proteica e mineral dos animais (Wittiwer $2000 \mathrm{a}, 2000 \mathrm{~b}$ ) possibilitando assim analisar mudanças e realizar ajustes que possam ser imprescindíveis para minimizar a prevalência e incidência de enfermidades durante o período de transição (LeBlanc et al. 2006, Duffield \& LeBlanc 2009, Goff 2009).

Objetivou-se com este estudo avaliar o perfil metabólico de vacas da raça Holandesa durante o período de transição, através de mensurações de concentrações séricas de: ácidos graxos não esterificados, beta hidroxibutirato, colesterol, cálcio, fósforo, magnésio, proteína total, albumina e as enzimas hepáticas AST e LDH.

\section{MATERIAL E MÉTODOS}

O presente trabalho faz parte de um grupo de experimentos que tiveram seus procedimentos aprovados pelo Comitê de Ética em Experimentação Animal da UFMG (CETEA 82/2011). 0 trabalho foi realizado entre os meses de outubro a dezembro de 2012. Durante este período a temperatura ambiental média para a região de Inhaúma, segundo o Instituto Nacional de Meteorologia (INMET), foi de $24,85^{\circ} \mathrm{C}$ com máxima de $34,1^{\circ} \mathrm{C}$ e mínima de $13,8^{\circ} \mathrm{C}$. A precipitação pluviométrica média foi de $171,2 \mathrm{~mm} / \mathrm{mês}$. Foram utilizadas doze vacas da raça Holandesa provenientes de uma fazenda comercial de produção leiteira, localizada no município de Inhaúma, Minas Gerais, a 86 km de Belo Horizonte. Os animais estavam entre a segunda e a quarta lactação e foram avaliados a partir de três semanas pré parto previsto até três semanas pós parto. As condições e rotina de manejo adotadas pela propriedade foram mantidas durante todo o período de realização do experimento. Trinta dias antes da data prevista para o parto os animais foram conduzidos para o lote de pré-parto, sendo manejados em galpão free-stall com acesso a piquete. Neste local os animais eram observados 24 horas sendo os partos supervisionados e, quando necessário, auxiliados.

A alimentação consistia em dieta total perfazendo $12,2 \mathrm{~kg}$ de MS/animal/dia sendo composta por silagem de milho $(69,5 \%)$, tifton verde (Cynodon dactylon) (8,27\%), farelo de soja (10,90\%), milho moído $(3,6 \%)$ e mistura mineral pré-parto $(7,7 \%)$. Contendo $15 \%$ de proteína bruta, $0,78 \%$ Cálcio, 0,42\% Fosforo, 0,53\% Magnésio, 1,17\% Potássio, 0,48\% Enxofre, 0,08\% Sódio, 0,60\% de Cloro, 42,80\% Fibra Detergente Neutro (FDN) e 30,92\% Carboidratos Não Fibrosos (CNF). A diferença cátion-aniônica (DCAD) da dieta foi de $-17,54 \mathrm{mEq} / 100 \mathrm{~g}$ de matéria seca. A dieta era fornecida uma vez ao dia pela manhã, distribuída em pista de alimentação com área linear de $70 \mathrm{~cm}$ por animal.

Logo após o parto as vacas recebiam, através de sonda oro-esofágica, 35 litros de solução eletrolítica (Drench) contendo $100 \mathrm{~g}$ de cloreto de potássio, $200 \mathrm{~g}$ de sulfato de magnésio, $100 \mathrm{~g}$ de cloreto de cálcio e $300 \mathrm{ml}$ de propilenoglicol. Posteriormente eram transferidas para outro galpão free-stall ("galpão de checagem"), onde permaneciam de 10 a 20 dias sendo monitoradas diariamente por um mesmo funcionário. A dieta total era fornecida, duas vezes ao dia, em pista de trato e eram realizadas três ordenhas diárias, com intervalos de 8 horas.

As coletas de sangue foram iniciadas três semanas pré-parto, com coletas semanais até o dia do parto, seguido de uma coleta ao parto e nos dias dois, cinco, 15 e 21 após o parto, totalizando oito coletas por animal e 96 amostras no total. Foram realizadas quatro a cinco horas após a primeira alimentação do dia. Para realiza- 
ção do perfil metabólico, $5 \mathrm{ml}$ de sangue foram colhidos através de punção de veia jugular após antissepsia local com álcool iodado a $2 \%$, em dois tubos vacutainer siliconizados com gel ativador de coágulo. Após coletadas, as amostras foram centrifugadas por 10 minutos a 3.800 RPM. Na sequência o soro foi fracionado e armazenado em quatro microtubos de congelamento de $0,5 \mathrm{ml}$, identificados e congelados a $-20^{\circ} \mathrm{C}$. As análises de soro foram realizadas em analisador bioquímico automático (COBAS Mira Plus ${ }^{\circledR}$ ). Foram utilizados kits comerciais RANDOX $^{\circledR}$ para dosagens de ácidos graxos não esterificados (AGNE) e beta hidroxibutirato (BHBA) e SYNERMED ${ }^{\circledR}$ para colesterol (COLES), cálcio (Ca), fósforo (P), magnésio (Mg), albumina (ALB), proteína total (PT), aspartato aminotransferase (AST) e lactato desidrogenase (LDH).

Para a avaliação do perfil metabólico utilizou-se o delineamento em blocos ao acaso. As variáveis COL, MAG, AST e AGNE violaram os princípios de normalidade e homocedasticidade, sendo, portanto submetidas a transformação logarítmica (COLES, Mg, AST) ou raiz (AGNE). As médias entre os momentos de colheita foram comparadas pelo teste de Scott-Knott com 5\% de significância. As análises estatísticas foram realizadas utilizando-se SAEG 9.1 (Universidade Federal de Viçosa-UFV, 1998). Para avaliação da relação entre as variáveis estudadas foi realizada análise multivariada dos componentes do perfil metabólico no sistema Infostat.

\section{RESULTADOS}

As concentrações médias de AGNE e BHBA apresentaram aumento $(\mathrm{p}<0,05)$ no período pós-parto em relação ao pré-parto. Já as concentrações séricas médias de COLES variaram entre os momentos avaliados. Esses resultados estão apresentados no Quadro 1 e seus comportamentos estão representados na Figura 1. Os valores de AGNE foram mais elevados no período pós parto do que no pré parto $(\mathrm{p}<0,05)$. Não houve diferença entre os momentos do período pré-parto, assim como entre os do período pós-parto $(p>0,05)$. Os valores de AGNE permaneceram próximos a $0,2 \mathrm{mmol} / \mathrm{L}$ no pré-parto e aumentaram no dia do parto mantendo-se em torno de $0,4 \mathrm{mmol} / \mathrm{L}$ até três semanas pós parto. Nenhuma vaca apresentou valor superior a $0,4 \mathrm{mmol} / \mathrm{L}$ no pré-parto e apenas uma teve valor superior a $0,7 \mathrm{mmol} / \mathrm{L}$ após o parto. A concentração média de BHBA variou de $0,40 \mathrm{mmol} / \mathrm{L}$ no pré-parto para $0,62 \mathrm{mmol} / \mathrm{L}$ no pós-parto. No pré-parto, as concentrações séricas médias de COLES apresentaram valores semelhantes até a segunda semana pós-parto, declinando a partir da primeira semana

Quadro 1. Concentrações séricas médias (mmol/L) de AGNE e BHBA e (mg/dL) de COLES em vacas multíparas da raça Holandesa na terceira ( $-3 \mathrm{sem})$, segunda ( -2 sem) e primeira (-1 sem) semanas pré-parto, parto e nos dias 2, 5, 15 e 21 pós-parto em sistema intensivo de criação

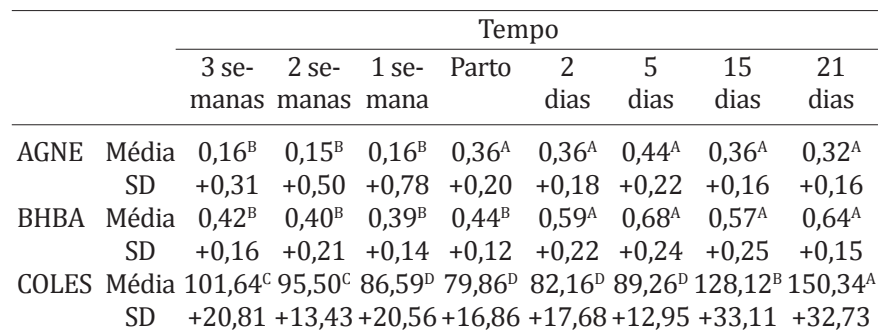

Médias seguidas por letras maiúsculas distintas nas linhas diferem entre si pelo teste de Scott-Knott $(\mathrm{p}<0,05)$. $(\mathrm{p}<0,05)$ e mantendo-se estáveis até o quinto dia pós-parto. A partir daí ocorreu aumento progressivo, atingindo seu maior valor $(150,34 \mathrm{mg} / \mathrm{dL}) 21$ dias após o parto. No dia do parto ocorreu o menor valor da concentração de COL circulante, $79,86 \mathrm{mg} / \mathrm{dL}$.

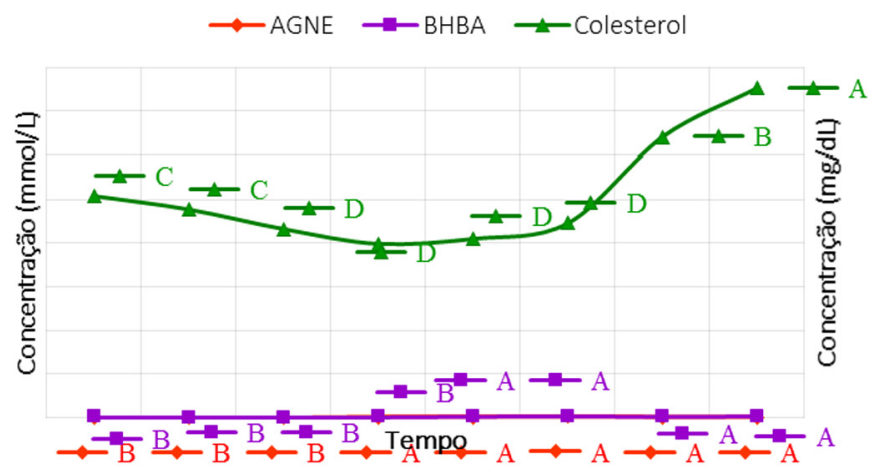

Fig.1. Comportamento das concentrações séricas médias (mmol/L) de ácidos graxos não esterificados (AGNE), beta hidroxibutirato (BHBA) de colesterol (COLES) e (mg/dL) em vacas multíparas da raça Holandesa na terceira (-3 sem), segunda ( $-2 \mathrm{sem})$ e primeira ( $-1 \mathrm{sem})$ semanas pré-parto, parto e nos dias 2, 5, 15 e 21 pós-parto em sistema intensivo de criação. Médias seguidas por letras distintas nas linhas diferem entre si pelo teste de Scoot-Knott $(\mathrm{p}<0,05)$.

Quadro 2. Concentrações séricas médias (g/dL) de proteína total e albumina de vacas multíparas da raça holandesa na terceira ( $-3 \mathrm{sem})$, segunda ( $-2 \mathrm{sem})$ e primeira (-1 sem) semanas pré-parto, parto e nos dias $2,5,15$ e 21 pós-parto em sistema intensivo

Período de transição

-3 sem -2 sem -1 sem Parto 2 dias 5 dias 15 dias 21 dias

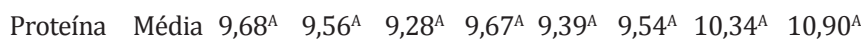

$\begin{array}{lllllllll}\text { total SD } & +1,72 & +2,22 & +1,38 & +1,6 & +1,99 & +2,49 & +1,95 & +2,4\end{array}$

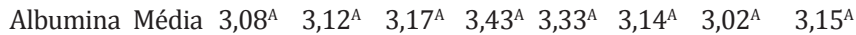

SD $+0,48+0,52+0,56+0,54+0,58+0,67+0,60+0,56$

Médias seguidas por letras maiúsculas distintas nas linhas diferem entre si pelo teste de Scott-Knott $(\mathrm{p}<0,05)$.

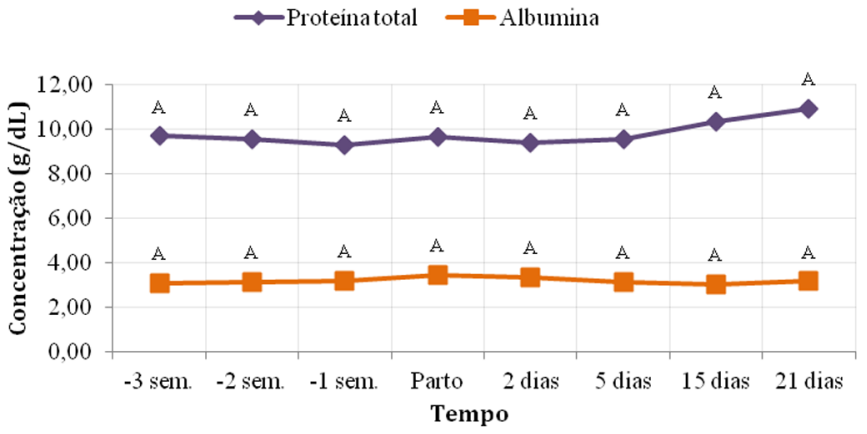

Fig.2. Comportamento das concentrações séricas médias (g/dl) de proteína total e albumina de vacas multíparas da raça holandesa na terceira ( $-3 \mathrm{sem})$, segunda ( $-2 \mathrm{sem})$ e primeira $(-1$ sem) semanas pré-parto, parto e nos dias 2, 5, 15 e 21 pós-parto em sistema intensivo de criação. Médias seguidas por letras distintas nas linhas diferem entre si pelo teste de Scott-Knott $(\mathrm{p}<0,05)$. 
As concentrações séricas médias de proteína total e albumina não apresentaram diferenças $(p>0,05)$ entre os momentos pré e pós-parto (Quadro 2, Fig.2). Os valores de PT permaneceram praticamente constantes entre os momentos avaliados e estão situados acima do limite superior do valor de referência de 6,8-8,6g/dL (Smith 2006). Apenas dois animais apresentaram hipoproteinemia na terceira semana pré-parto e no quinto dia pós- parto, com valores de 6,2 e 6,30g/dL respectivamente. As concentrações séricas médias de ALB também não apresentaram diferenças entre os momentos e permaneceram dentro dos valores de referência de 2,5-3,6g/dL (Smith 2006). Quatro animais apresentaram hipoalbuninemia durante um único momento com valores próximos a $2,3 \mathrm{~g} / \mathrm{dL}$.
As atividades das enzimas AST e LDH demonstraram aumento após o parto $(\mathrm{p}<0,05)$ (Quadro 3, Fig.3). Ocorreu aumento da atividade enzimática no dia do parto permanecendo alta no pós-parto em relação ao pré-parto. Entretanto os valores de AST e LDH se mantiveram dentro dos valores de referência mencionados pela literatura, 78-132 U/L e 692-1445 U/L respectivamente (Kaneko et al. 2008).

Os minerais foram analisados através de suas médias, uma em relação ao tempo pré e pós-parto e outra pela proporção, em cada momento, de amostras com valores abaixo ou acima dos limites de referência. Não houve diferença $(\mathrm{P}>0,05)$ nas concentrações séricas médias de $\mathrm{Ca}, \mathrm{P}$ e $\mathrm{Mg}$ entre os momentos de colheita (Quadro 4 e Fig.4). As concentrações médias de Ca se mantiveram estáveis permane-

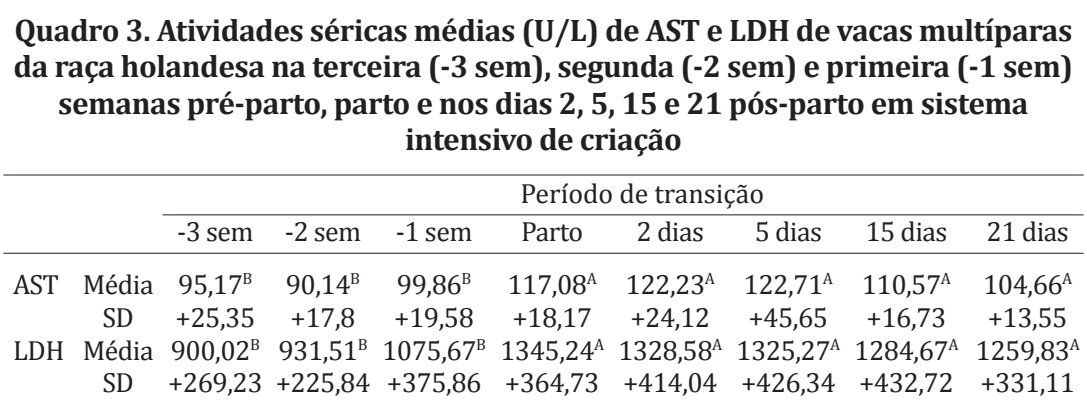

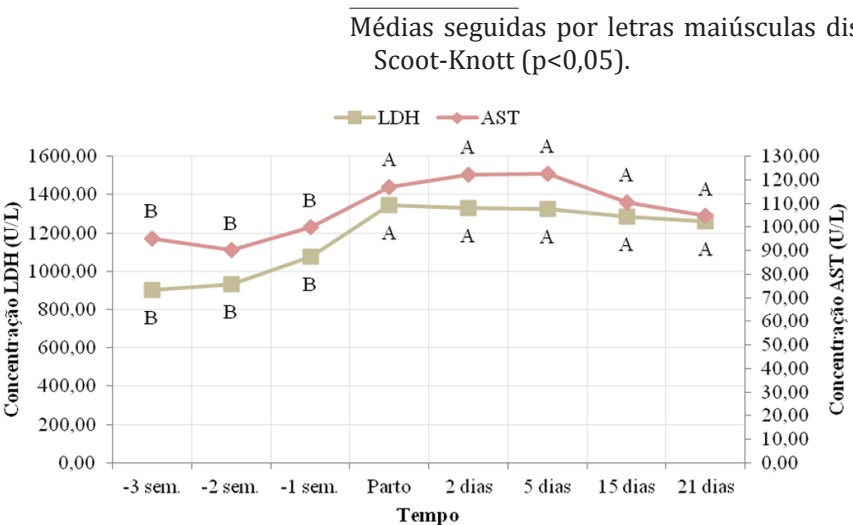

Fig.3. Comportamento das atividades séricas médias (U/L) de AST e LDH de vacas multíparas da raça holandesa na terceira ( $-3 \mathrm{sem})$, segunda ( $-2 \mathrm{sem})$ e primeira ( $-1 \mathrm{sem})$ semanas pré-parto, parto e nos dias $2,5,15$ e 21 pós-parto em sistema intensivo de criação. Médias seguidas por letras distintas nas linhas diferem entre si pelo teste de Scott-Knott $(\mathrm{p}<0,05)$.

Quadro 4. Concentrações séricas médias (mg/dl) de cálcio total (Ca), fósforo (P), e magnésio (Mg) de vacas multíparas da raça holandesa na terceira ( -3 sem), segunda ( -2 sem) e primeira (-1 sem) semanas pré-parto, parto e nos dias 2,5 , 15 e 21 pós-parto em sistema intensivo de criação

\begin{tabular}{ccccccccccc}
\hline & \multicolumn{8}{c}{ Período de transição } \\
\cline { 2 - 10 } & & -3 sem & -2 sem & -1 sem & Parto & 2 dias & 5 dias & 15 dias & 21 dias \\
\hline Ca & Média & $10,31^{\mathrm{A}}$ & $10,6^{\mathrm{A}}$ & $10,82^{\mathrm{A}}$ & $10,01^{\mathrm{A}}$ & $10,52^{\mathrm{A}}$ & $11,22^{\mathrm{A}}$ & $10,49^{\mathrm{A}}$ & $10,62^{\mathrm{A}}$ \\
& SD & $+1,19$ & $+1,31$ & $+1,21$ & $+1,12$ & $+1,81$ & $+1,35$ & $+1,42$ & $+1,26$ \\
$\mathrm{P}$ & Média & $8,29^{\mathrm{A}}$ & $7,92^{\mathrm{A}}$ & $8,39^{\mathrm{A}}$ & $5,72^{\mathrm{A}}$ & $7,3^{\mathrm{A}}$ & $8,49^{\mathrm{A}}$ & $7,82^{\mathrm{A}}$ & $7,81^{\mathrm{A}}$ \\
& SD & $+1,94$ & $+1,73$ & $+4,07$ & $+3,34$ & $+2,2$ & $+3,15$ & $+1,68$ & $+3,35$ \\
Mg Média & $2,72^{\mathrm{A}}$ & $2,86^{\mathrm{A}}$ & $2,68^{\mathrm{A}}$ & $3,09^{\mathrm{A}}$ & $2,61^{\mathrm{A}}$ & $2,38^{\mathrm{A}}$ & $2,4^{\mathrm{A}}$ & $2,64^{\mathrm{A}}$ \\
& SD & $+0,72$ & $+0,94$ & $+0,81$ & $+0,57$ & $+0,33$ & $+0,42$ & $+0,36$ & $+1,28$
\end{tabular}

Médias seguidas por letras maiúsculas distintas nas linhas diferem entre si pelo teste de Scott-Knott $(\mathrm{p}<0,05)$.

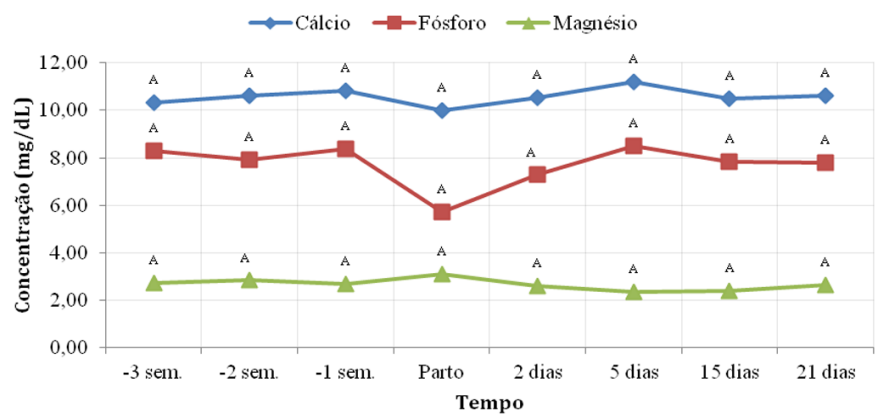

Fig.4. Comportamento das concentrações séricas médias (mg/dL) de cálcio total, fósforo e magnésio de vacas multíparas da raça holandesa na terceira ( $-3 \mathrm{sem})$, segunda ( $-2 \mathrm{sem})$ e primeira (-1 sem) semanas pré-parto, parto e nos dias 2, 5, 15 e 21 pós-parto em sistema intensivo de criação. Médias seguidas por letras distintas nas linhas diferem entre si pelo teste de Scott-Knott $(\mathrm{p}<0,05)$.

cendo em torno de $10,6 \mathrm{mg} / \mathrm{dL}$, próximas ao limite superior do valor de referência de $8,5-10 \mathrm{mg} / \mathrm{dL}$ (Goff 2004). A menor média de concentração sérica de Ca foi de $10,01 \mathrm{mg} /$ $\mathrm{dL}$ no dia do parto. Em relação às concentrações de $\mathrm{P}$, não foram observadas diferenças entre os momentos $(p>0,05)$ estando as concentrações séricas médias no limite superior do valor de referência (4-8mg/dL) (Goff 2000). Nenhum animal apresentou hipofosfatemia durante o período experimental. Os valores de Mg sérico encontrados neste estudo também não diferiram entre os momentos $(\mathrm{p}>0,05)$. Todas as concentrações séricas médias permaneceram dentro dos valores de referência $(1,7-3,3 \mathrm{mg} / \mathrm{dL}$ ) (Reinhardt et al. 1988). A maior concentração média sérica foi $3,09 \mathrm{mg} / \mathrm{dL}$ no dia do parto. Apenas um animal apresentou hipomag- 


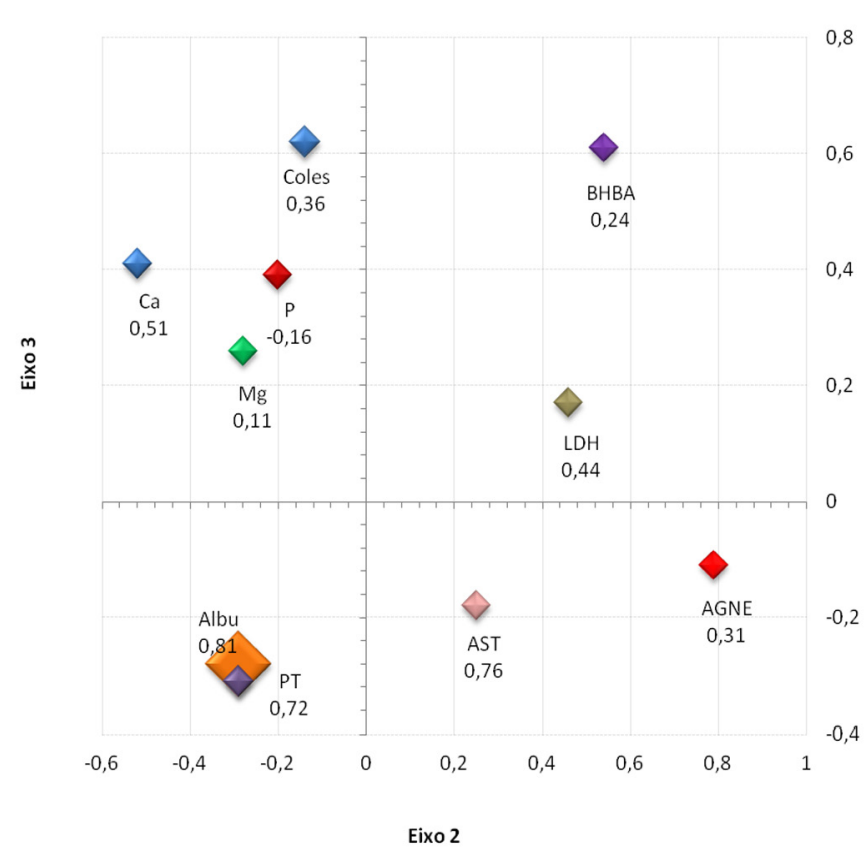

Fig.5. Representação gráfica das variáveis (AGNE, BHBA, Coles, proteina total, albumina, AST, LDH, cálcio, fósforo e magnésio) no sistema tridimensional obtida na análise multivariada em componentes principais, segundo os Eixos 2 e 3. As coordenadas do Eixo 1 estão registradas abaixo da sigla das variáveis no gráfico. Inércia do sistema: $57 \%$.

nesemia no dia cinco após o parto $(1,67 \mathrm{mg} / \mathrm{dL})$, entretanto este não apresentou hipocalcemia.

A fim de avaliar a relação das forças entre as variáveis apresentadas anteriormente foi empregada uma análise multivariada (Fig.5). No presente trabalho observou-se uma forte associação entre Albu e PT, uma associação positiva moderada entre BHBA e LDH e também moderada entre AGNE e AST. Observou-se também um antagonismo das variáveis Albu e PT ao LDH, e com maior intensidade ao BHBA. As variáveis Coles, Ca e Mg apresentaram associação positiva moderada entre si, além de um antagonismo decrescente, nessa ordem, ao AST e mais intenso ao AGNE. O $\mathrm{P}$ demonstrou um antagonismo crescente, nesta ordem, à Albu, LDH, BHBA, AST e AGNE.

\section{DISCUSSÃO}

Baseando-se nos resultados apresentados no Quadro 1, no presente rebanho ocorreu BEN de baixa intensidade, uma vez que, esses animais não apresentaram concentrações de AGNE elevadas. Segundo alguns autores (Cameron et al. 1998, Ospina et al. 2010a, 2010b, Chapinal et al. 2011, Roberts et al. 2012) as concentrações de AGNE acima de $0,4 \mathrm{mmol} / \mathrm{L}$ no pré-parto ou acima de $0,7 \mathrm{mmol} / \mathrm{L}$ no pós-parto estão relacionados com maior ocorrência de várias enfermidades no período de transição, sendo um fator de risco para a saúde das vacas no período pós-parto.

0 aumento dos valores de AGNE, observado a partir do dia do parto, é descrito por vários autores (Schwalm \& Schultz 1976, Guretzky et al. 2006, Lien et al. 2010) e, segundo Reynolds et al. (2003), tal aumento se deve a maior liberação de AGNEs para a veia porta no início da lactação, em decorrência da rápida mobilização de gordura localizada no mesentério e omento das vacas. Portanto, a concentração de AGNEs é o reflexo da magnitude de mobilização das reservas corporais e começa a aumentar alguns dias antes do parto, tendo como objetivo fornecer energia para suprir as necessidades do organismo (Bell 1995, Duffied \& LeBlanc 2009, LeBlanc et al. 2005, LeBlanc 2010). Frigotto (2010) utilizando um ponto de corte de $0,6 \mathrm{mmol} / \mathrm{L}$ de AGNE no pós-parto, encontrou $56,2 \%$ dos animais acima desse limite no primeiro dia após o parto, $48,6 \%$ no quinto dia e $34,3 \%$ no décimo dia. Garcia (2010), trabalhando com o limite de $0,7 \mathrm{mmol} / \mathrm{L}$, observou $12,1 \%$ dos animais com níveis acima deste no pós-parto. A intensidade do BEN decorrente da diminuição da ingestão de matéria seca e do aumento das exigências nutricionais é responsável por aquela mobilização (Bauman \& Currie 1980, Vazquez-Añon et al. 1994, Bell et al. 1995, Grummer 1995). Ao parto ocorre mudança no metabolismo do tecido adiposo, o qual passa de lipogênese para lipólise (Bell 1995).

As concentrações séricas médias de BHBA apresentadas no Quadro 1 e na Figura 1 demonstram que houve diferença entre pré-parto e pós-parto $(\mathrm{p}<0,05)$. Durante o pré-parto as concentrações de BHBA circulante permaneceram constantes apresentando aumento dois dias após o parto $(\mathrm{p}<0,05)$. O BHBA é um dos principais corpos cetônicos produzidos pelo fígado e importante indicador do BEN na vaca (Ospina et al. 2010b). 0 aumento da concentração sérica de corpos cetônicos ocorre quando a quantidade de AGNE excede a capacidade de oxidação pelo fígado (Drackley 1999, Li et al. 2012). A interação entre AGNE e BHBA pode ser observada pelo comportamento de suas concentrações na Figura 1. Os aumentos nas concentrações de BHBA ocorrem momentos após o aumento das concentrações de AGNE (Busato et al. 2002, Doepel et al. 2002, Cavestany et al. 2005). A elevação do valor de BHBA após o parto é descrita por vários autores (Doepel et al. 2002, Bertoni et al. 2008, Lien et al. 2010, Cincovic et al. 2012), que observaram maiores valores na primeira semana pós-parto. Vazquez-Añon et al. (1994) também encontraram aumento de BHBA no dia seguinte ao parto, porém seu maior valor foi observado no décimo dia pós-parto. LeBlanc et al. (2005) observaram aumento de BHBA uma semana antes do parto, refletindo a precoce mobilização de reservas corporais. Como descrito anteriormente, a intensidade do BEN esta relacionada a intensidade de mobilização de AGNE e consequentemente na produção de BHBA (Drackley 1999, Ospina et al. 2010b, Li et al. 2012).

No Brasil, resultados similares, aos encontrados no presente estudo, para variação média de BHBA entre o pré-parto e o pós-parto foram relatados por Moreira (2013) com valores de $0,41 \mathrm{mmol} / \mathrm{L}$ e $0,68 \mathrm{mmol} / \mathrm{L}$ respectivamente. Não houve diferença na concentração média de BHBA no pós-parto $(\mathrm{p}>0,05)$. Resultados diferentes foram encontrados por Frigotto (2010) e por Chung et al. (2008), onde valores mais altos de BHBA ocorreram no quinto dia após o parto. Segundo LeBlanc et al. (2005) a concentração de BHBA aumenta ligeiramente nos últimos três dias que antecedem o parto, mas seu aumento é ex- 
pressivo após o parto, atingindo o pico no quinto dia de lactação. Garcia (2010) e Moreira (2013) encontraram a maior concentração sérica média no quinto dia após o parto, sendo $0,59 \pm 0,76$ e $0,79 \pm 0,77 \mathrm{mmol} / \mathrm{L}$. Segundo Oetzel (2004), valores superiores $1,2 \mathrm{mmol} / \mathrm{L}$ são indicativos de cetose subclínica e estão relacionados com diminuição da saúde do rebanho. No presente estudo, um animal apresentou o valor $1,1 \mathrm{mmol} / \mathrm{L}$ no quinto dia pós-parto, e outro $1,15 \mathrm{mmol} / \mathrm{L}$ no décimo quinto dia pós-parto, indicando que nenhum animal apresentou cetose subclínica. Moreira (2013) encontrou a maior concentração média de BHBA no dia cinco (5) após o parto, juntamente com a maior frequência de cetose subclínica $(13,3 \%$ no verão e $9,68 \%$ no inverno). Garcia (2010) trabalhando com ponto de corte de $1,4 \mathrm{mmol} / \mathrm{dL}$ BHBA relatou $24 \%$ de cetose subclínica.

No presente estudo, a diminuição da concentração média de COL no pré-parto e no dia do parto sugerem diminuição moderada no consumo. A diminuição na síntese de COL ocorre quando há restrição alimentar, levando a menor concentração de insulina e aumento de glucagon. Por isso, normalmente a concentração de COL está ligada à ingestão de alimentos, havendo comportamento similar entre estes (Grummer 1995). Segundo Guretzky et al. (2006) a concentração de COL inferior a $77,34 \mathrm{mg} / \mathrm{dL}$ esta associada a baixo consumo voluntário ou a problemas metabólicos (Grummer 1995, Grum et al. 1996). Kaneko et al. (2008) recomenda o limite de $80 \mathrm{mg} / \mathrm{dL}$. No Brasil, Pogliani \& Birgel (2007) trabalhando com bovinos da raça Holandesa, no estado de São Paulo, encontraram valores de $94,63-146,93 \mathrm{mg} / \mathrm{dl}$ para vacas com seis a nove meses de gestação, e 94,06-27,03mg/dL para animais no pós-parto.

0 aumento do cortisol próximo ao parto é outro fator que contribui para a diminuição na concentração do colesterol. 0 glicocorticoide inibe a atividade enzimática no processo de síntese do COL, a 3-hidroxi-3methilglutaril-CoA redutase (Kaneko et al. 2008). A redução nas concentrações de colesterol com a aproximação do parto e seu aumento no pós-parto também foi observada por outros autores (Schwalm \& Schultz 1976, Van den Top et al. 1995a, 1995b, 1996, Kaneene et al. 1997). Stengärde et al. (2008) e Van Dorland et al. (2009) encontraram resultados semelhantes, relacionando o aumento das concentrações de COL pós- parto ao aumento de consumo com elevação da captação de lipídeos pelo fígado e melhora no balanço energético negativo. Garcia (2010), trabalhando com vacas da raça Holandesa de produção média diária de 32 litros, encontrou comportamento similar ao deste estudo, com $88,16 \mathrm{mg} / \mathrm{dl}$ na primeira semana pré-parto e $136 \mathrm{mg} / \mathrm{dL}$ na quarta semana após o parto. Altas concentrações de COL em vacas no pós-parto fazem parte do processo fisiológico. $\mathrm{O}$ aumento de mobilização tecidual promovida pela demanda energética e o aumento da síntese de lipoproteínas e hormônios esteroides são os responsáveis por este processo (Margolles 1983, Aeberhard et al. 2001).

Não foram observadas alterações na concentração de PT, embora sua diminuição próxima ao parto seja descrita por Moraes et al. (1997), devido à mobilização de imunoglobulinas para composição do colostro, principalmente IgG.
O comportamento da ALB no período de transição é descrito na literatura, com vários resultados distintos, não havendo concordância ou um comportamento típico. Assim como no presente estudo, Fagliari et al. (1998) e Garcia (2010) não encontraram diferenças nos valores de ALB entre o parto até 30 dias após, entretanto Feitosa \& Birgel (2000) observaram valores menores de albumina no dia do parto com posterior aumento. Já Gonçalves \& Kozicki (1997) descreveram diminuição das concentrações séricas de ALB pós-parto. As alterações nos valores de concentrações de ALB podem estar relacionadas à repartição da proteína para glândula mamária e preparação da lactação, além da síntese hepática (Moorby et al. 2000, Park et al. 2010). O aumento de sua concentração após o parto se deve provavelmente ao aumento da síntese proteica que ocorre neste período (Bell 1995), além da desidratação e do estresse calórico, fatores que podem aumentar suas concentrações em decorrência à hemoconcentração.

0 aumento da atividade das enzimas AST e LDH, porém dentro de valores fisiológicos, no dia do parto permanecendo alta no pós-parto, reflete a mudança no metabolismo hepático, em função principalmente da produção de leite (Reynolds et al. 2003). De Paula et al. (2011), relataram maior atividade de LDH no dia do parto, com média de 724,92 249 ,63 U/L, com posterior diminuição no pós-parto. Apesar de a AST estar presente no fígado e também em células musculares, sua elevação no período de transição, pode indicar maior atividade hepática (Thrall et al. 2012). Resultados semelhantes foram encontrados por Aeberhard et al. (2001) e Moreira (2013). Aquino Neto (2012) encontrou aumento de sua atividade 24 horas após o parto, concomitante com a elevação das concentrações de BHBA e relacionou este fato como sendo indicativo do incremento no metabolismo hepático. Fagliari et al. (1998) também encontraram aumento da atividade de AST após o parto atribuindo este achado ao esforço muscular ocorrido durante o processo de parto. Aeberhard et al. (2001) relataram aumento de AST ao parto até a segunda semana pós-parto, com posterior tendência a diminuir. Resultados similares foram observados por Moreira (2013). Entretanto, Birgel Junior et al. (2003), trabalhando com animais da raça Holandesa no Estado de São Paulo, não encontraram alterações significativas na atividade de AST. Assim como De Paula et al. (2011) que, trabalhando com animais mestiços, também não observou diferença na atividade enzimática de AST durante o peri-parto.

A metodologia de avaliação da proporção, em cada momento, dos níveis séricos dos minerais, realizadas neste estudo, são de extrema importância pois, além de informar sobre a homeostase dos minerais,fornece o diagnóstico da ocorrência de distúrbios como hipocalcemia, hipomagnesemia e híper ou hipofosfatemia (Oetzel 2004, Duffield \& LeBlanc 2009, Goff 2009).

Vários trabalhos verificaram a redução da calcemia com aproximação do parto, sendo o menor valor, observado no dia do parto (Goff \& Horst 1997a, 1997b, NRC 2001, Souza Junior 2008, Buture 2009, Moreira 2013). Tal fato não foi observado neste experimento, uma vez que, as concentrações médias de cálcio ao parto mantiveram-se estáveis 
e acima do limite superior do valor de referência de 8,5$10 \mathrm{mg} / \mathrm{dL}$ (Goff 2004). As concentrações séricas médias de Ca se mantiveram durante todo o período de transição acima daquelas consideradas como ponto de corte para hipocalcemia subclínica (8,5mg/dl) (Goff 2000). No entanto, a literatura descreve que a média geral de animais hipocalcêmicos no dia do parto está próxima dos 50\% (Reinhardt et al. 1988, Goff \& Horst 1997b, Goff 2008, Souza Junior 2008, Goff \& Kimura 2009, Moreira 2013). Por outro lado, Frigotto (2010), trabalhando com vacas Holandesas confinadas (free-stall) e o limite inferior de 7,5mg de $\mathrm{Ca} / \mathrm{dL}$, encontrou menores porcentagens de animais hipocalcêmicos nos dias 1 e 2 pós-parto (11,3 e 4,7\%, respectivamente). Segundo Reinhardt et al. (1988) vários são os fatores que podem interferir na homeostase do $\mathrm{Ca}$, como a composição da dieta, idade, sexo e raça. No presente estudo, os resultados demonstram manutenção das concentrações séricas de Ca acima do limite fisiológico inferior, e menor ocorrência de hipocalcemia subclínica, possivelmente associados com a dieta e o conforto dos animais durante o período de transição. No entanto, foram encontrados 16,7\% (2/12) de frequência de hipocalcemia no dia 15 pós-parto, sinalizando um estado de alerta para este período.

No presente estudo não houve associação entre os animais que apresentaram hipocalcemia e a redução na concentração de P. Alguns autores relatam a redução na concentração de $\mathrm{P}$ no dia do parto e durante os episódios de hipocalcemia (Reinhardt et al. 1988, Goff \& Host 1998, NRC 2001). Tal fato parece estar relacionado à ação do paratormônio, responsável em promover a perda renal e salivar de $\mathrm{P}$, acarretando assim a diminuição da sua concentração sérica (Goff 2000). Similar ao achado do presente estudo, Souza Junior (2008) não observou diferença nos níveis de P durante o $14^{\circ}$ dia pré-parto até o $21^{\circ}$ dia pós-parto. De Paula et al. (2011) também não encontraram variação na concentração de $\mathrm{P}$ entre três semanas pré-parto até três semanas pós-parto, sendo também relatada uma prevalência muito baixa de hipofosfatemia por Moreira (2013).

A manutenção das concentrações adequadas de $\mathrm{Mg}$ contribui para os resultados em relação à calcemia, uma vez que a reabsorção óssea de Ca é dependente do Mg (Goff 2004 , 2008). Trabalhos realizados no Brasil por Souza Júnior (2008), Buture (2009) e Moreira (2013) relataram não haver variação no $\mathrm{Mg}$ antes do parto, parto e nos dias após o parto, embora as concentrações descritas sejam inferiores aos encontrados neste estudo e próximos ao limiar de $1,7 \mathrm{mg} / \mathrm{dL}$. Entretanto alguns autores observaram elevação nas concentrações de Mg no dia do parto (Marquardt et al. 1976, Wilson et al. 1977). Tal variação relatada na literatura está relacionada ao equilíbrio entre a utilização deste mineral para produção de colostro e sua reposição através da dieta, paralelamente a absorção óssea e a diminuição da excreção renal pela ação do paratormônio. Por não apresentar regulação própria, o equilíbrio nas concentrações de Mg esta diretamente relacionado a dieta fornecida aos animais (NRC 2001, Goff 2004).

Baseando-se nos achados apresentados pela anáise multivariada (Fig. 5), podemos observar uma forte associação entre Albu e a PT, uma vez que, se apresentam no mesmo quadrante e de forma sobreposta. Ambas são sintetizadas pelo fígado e estão relacionadas ao metabolismo hepático (Kaneko et al. 2008). Cerca de 50-65\% da PT circulante são representadas pela Albu, sendo um importante componente daquela (Kaneko et al. 2008, Smith 2006). Tal fato explica a alta associação e relação encontrada entre estas variáveis no presente estudo. 0 afastamento dessas variáveis é sugestivo da presença de um processo inflamatório, ou seja há um aumento na concentração da PT e uma queda nas concentrações de ALB associado a um aumento das globulinas. Este fato é importante uma vez que nos indica uma baixa ocorrência de processos inflamatórios nos animais avaliados no presente estudo. Observou-se também antagonismo das variáveis Albu e PT ao LDH, fato que pode ser constatado pela posição desse no quadrante diagonalmente oposto. Assim como para o LDH, a Albu e PT apresentaram antagonismo ao BHBA, entretanto neste caso o antagonismo observado foi de maior intensidade, uma vez que além de situados em quadrantes diagonalmente opostos, as variáveis apresentaram distância maior. Esta oposição provavelmente relaciona-se com a capacidade adaptativa do fígado conforme as necessidades do organismo. Isto é, o órgão prioriza sua função metabólica de acordo com a demanda. A mobilização de reservas energéticas e síntese de BHBA com participação da enzima LDH é antagônica a síntese proteica para produção de leite. Já o BHBA e LDH apresentam associação positiva moderada.

A Albu está diretamente relacionada com a proteína total, o que significa que não ocorreu variação de globulina neste experimento. A Albu é uma proteína de fase aguda negativa, indicando que estes animais não apresentaram processo inflamatório (mastite, metrite, laminite). A globulina está estável e também sinaliza ausência de processos inflamatórios agudos ou crônicos (Thrall et al. 2012).

O colesterol (Coles), cálcio (Ca) e magnésio (Mg) experimentam associação positiva moderada. Nesta ordem, eles apresentam antagonismo decrescente ao AST e mais intensamente ao AGNE. AST e AGNE são moderadamente associados, pois estão em um mesmo quadrante. 0 fósforo (P) é antagônico à albumina (Albu), LDH, BHBA, AST e AGNE, sendo o antagonismo crescente nesta ordem. A inércia do sistema ideal seria acima de $70 \%$, no caso foram $57 \%$, entretanto representa um resultado considerável.

A associação positiva do cálcio e magnésio se deve ao fato do magnésio ser cofator de ligação entre o paratormônio e o receptor, sendo necessária sua presença para ocorrer à resposta do PTH e manter a homeostase de cálcio (Goff 2004, 2008). 0 magnésio não possui mecanismo homeostático de controle, sendo suas concentrações sanguíneas reflexo direto da alimentação (NRC 2001, Goff 2004). Assim sendo, a associação do cálcio, magnésio e colesterol pode estar relacionada ao consumo de alimento (Grummer 1995, Kaneko et al. 2008). De maneira oposta a este quadrante e antagônicos estão AGNE e AST. Maior mobilização de ácidos graxos não esterificados ocorre com a diminuição de ingestão de matéria seca, enquanto a atividade enzimática de AST está envolvida na mobilização tecidual, demonstrando associação com o AGNE. O AGNE aumenta quando há diminuição de consumo de alimentos, intensifi- 
cando o metabolismo hepático e determinando assim uma maior atividade de AST.

\section{CONCLUSÕES}

A avaliação do perfil metabólico demonstrou ser uma importante ferramenta de monitoramento para vacas de aptidão leiteira durante o período de transição.

Na situação estudada, as vacas no período de transição, apresentaram essencialmente alterações no perfil metabólico energético entre o pré-parto e o pós-parto.

Os resultados de AGNE, BHBA e COLES encontrados no presente estudo demonstram que os animais apresentaram balanço energético negativo discreto, indicando possivelmente que as medidas adotadas pela propriedade em relação ao manejo nutrição e conforto (densidade animal, espaço de cocho, climatização nos galpões) das vacas neste período estão atendendo as necessidades dos animais.

As medidas de manejo, conforto e alimentação empregadas na propriedade estudada, garantiram a manutenção da homeostase mineral no período de transição das vacas.

\section{REFERÊNCIAS}

Aeberhard K., Bruckmaier R.M. \& Blum J.W. 2001. Metabolic, enzymatic and endocrine status in high yielding dairy cows. Part 2. J. Vet. Med. A, Physiol. Pathol. Clin. Med. 48:111-127.

Aquino Neto H.M.A. 2012. Perfil hidroeletrolítico, ácido-base, metabólico e mineral de vacas leiteiras no pós-parto imediato e avaliação da fluidoterapia oral. Tese de Doutorado, Universidade Federal de Minas Gerais, Belo Horizonte. 121p.

Bauman D.E. \& Currie W.B. 1980. Partitioning of nutrients during pregnancy and lactation: A review of mechanisms involving homeostasis and homeorhesis. J. Dairy Sci. 63:1514-1529.

Baumgard L.H., Odens L.J., Kay J.K., Rhoads R.P., Van Baale M.J. \& Collier R.J. 2006. Does Negative Energy Balance (NEBAL) limit milk synthesis in early lactation? Anais 21ํ Annual Southwest Nutrition and Management Conference, Tempe, AZ, p.181-187.

Bell A.W. 1995. Regulation of organic nutrient metabolism during transition from late pregnancy to early lactation. J. Animal Sci. 73:2804-2819.

Bell A.W., Slepetis R. \& Ehrhardt R.A. 1995. Growth and accretion of energy and protein in the gravid uterus during late pregnancy in Holstein cows. J. Dairy Sci. 78:1954-1961.

Bertoni G., Trevisi E., Han X. \& Bionaz M. 2008. Effects of inflammatory conditions on liver activity in puerperium period and consequences for performance in dairy cows. J. Dairy Sci. 91:3300-3310.

Birgel Junior E.H., Neves F.S., Salvatore L.C.A., Mirandola R.M.S., Távora J.P.F. \& Birgel E.H. 2003. Avaliação da influência da gestação e do puerpério sobre a função hepática de bovinos da raça holandesa. Ars Vet. 19(2):172-178.

Burhans W.S., Bell A.W., Nadeau R. \& Knapp J.R. 2003. Factors associated with transition cow ketosis incidence in selected New England herds. J. Dairy Sci. 86(1):247.

Busato A., Faissle D., Kupfer U. \& Blum J.W. 2002. Body condition scores in dairy cows: associations with metabolic and endocrine changes in healthy dairy cows. J. Vet. Med. A, Physiol. Pathol. Clin. Med. 49:455-460.

Buture I.O. 2009. Avaliação metabólica de bovinos leiteiros no peri-parto como forma de diagnóstico precoce da hipocalcemia da vaca leiteira. Tese de Doutorado, Universidade Estadual de Londrina, Londrina. $173 \mathrm{f}$.

Cameron R.E., Dyk P.B., Herdt T.H., Kaneene J.B., Miller R., Bucholtz H.F., Liesman J.S., Vandehaar M.J. \& Emery R.S. 1998. Dry cow diet, management, and energy balance as risk factors for displaced abomasum in high producing dairy herds. J. Dairy Sci. 81:132-139.

Cavestany D., Blanc J.E., Kulcsar M., Uriarte G., Chilibroste P., Meikle A.,
Febel H., Ferraris A. \& Krall E. 2005. Studies of the transition cow under a pasture-based milk production system: metabolic profiles. J. Vet. Med. A Physiol. Pathol. Clin. Med. 52(1):1-7.

Chapinal N., Carson M., Duffield T.F., Capel M., Godden S., Overton M., Santos J.E. \& LeBlanc S.J. 2011. The association of serum metabolites with clinical disease during the transition period. J. Dairy Sci. 94:48974903.

Chung Y.M., Pickett M.M., Cassidy T.W. \& Varga G.A. 2008. Effects of prepartum dietary carbohydrate source and monensin on periparturient metabolism and lactation in multiparous cows. J. Dairy Sci. 91:2744-2758.

Cincovic R.M., Branislava B., Biljana R., Hristov S. \& Dokovic R. 2012. Influence of lipolysis and ketogenesis to metabolic and haematological parameters in dairy cows during periparturient period. Acta Vet. Beogra. 62(4):429-444.

Contreras P.A. 2000. Indicadores do metabolismo proteico utilizado nos perfis metabólicos de rebanhos, p.23-30. In: González F.H.D., Ospina H., Barcellos J.O. \& Ribeiro L.A.O. (Eds), Perfil Metabólico em Ruminantes: seu uso em nutrição e doenças nutricionais. Gráfica da UFRGS, Porto Alegre.

Dann H.M., Varga G.A. \& Putman D.E. 1999. Improving energy supply to late gestation and early postpartum dairy cows. J. Anim. Sci. 82:17781778.

De Paula V.M., Freitas M.D., Moreira T.F., Moreira G.H.F.A., Ferreira L.O., Salgado L.M., Leme F.O.P., Molina L.R., Carvalho A.U. \& Facury Filho E.J. 2011. Perfil mineral e bioquímico de vacas leiteiras no período de transição em um sistema semi-intensivo em Minas Gerais. Anais 9o Congresso Brasileiro de Buiatria, Goiânia, GO, p.650-654.

Doepel L., Lapierre H. \& Kennelly J.J. 2002. Peripartum performance and metabolism of dairy cows in response to prepartum energy and protein intake. J. Dairy Sci. 85:2315-2334.

Drackley J.K. 1999. Biology of dairy cows during the transition period: The final frontier? J. Dairy Sci. 82:2259-2273.

Drackley J.K., Dann H.M., Douglas G.N., Nicole A., Guretzky J., Litherland N.B., Underwood J.P. \& Loor J.J. 2005. Physiological and pathological adaptations in dairy cows that may increase susceptibility to periparturient diseases and disorders. Ital. J. Anim. Sci. 4:323-344.

Duffield T.F. \& LeBlanc S.J. 2009. Interpretation of serum metabolic parameters around the transition period. Anais $24^{\text {a }}$ Southwest nutrition and management conference, Tucson, AZ, p.106-114.

Fagliari J.J., Santan A.E., Marchio W., Campos Filho E. \& Curi P.R. 1998. Constituintes sanguíneos de vacas das raças Nelore (Bos indicus) e Holandesa (Bos taurus) e de bubalinos (Bubalus bubalis) da raça Murah durante a gestação, no dia do parto e no puerpério. Arq. Bras. Med. Vet. Zootec. 50(3):273-282.

Feitosa F.L.F. \& Birgel E.H. 2000. Variação da concentração de imunoglobulinas G e M, de proteína total e sua frações eletroforéticas e da atividade da gamaglutamiltransferase no soro sanguíneo de vaca holandesas, antes e após o parto. Arq. Bras. Med. Vet. Zootec. 52(2):111-116.

Frigotto T.A. 2010. Monitoramento clínico e produtivo de vacas leiteiras no período de transição. Dissertação de Mestrado, Universidade Federal do Paraná, Curitiba. 61p.

Garcia A.M.B. 2010. Avaliação metabólica de vacas leiteiras submetidas a diferentes estratégias de prevenção do balanço energético negativo no pós-parto. Dissertação de Mestrado, Universidade Federal do Rio Grande do sul, Porto Alegre. 66p.

Goff J.P. 2000. Pathophysiology of calcium and phosphorus disorders. Vet. Clin. North Am., Food Anim. Pract. 16:319-337.

Goff J.P. 2004. Macromineral disorders of the transition cow. Vet. Clin. North Am., Food Anim. Pract. 20(3):471-494.

Goff J.P. 2006. Macromineral physiology and application to the feeding of the dairy cow for prevention of milk fever and other periparturient mineral disorders. Anim. Feed Sci. Technol. 126:237-257.

Goff J.P. 2008. The monitoring, prevention, and treatment of milk fever and subclinical hypocalcemia in dairy cows. Vet. J. 176:50-57.

Goff J.P. 2009. Como controlar a febre do leite e outras desordens metabólicas relacionadas à macro minerais em vacas de leite. Anais $13^{\circ}$ Curso 
novos enfoques na produção e reprodução de bovinos, Uberlândia, MG, p.267-284.

Goff J.P. \& Horst R.L. 1997a. Effects of the addition of potassium or sodium, but not calcium, to prepartum rations on milk fever in dairy cows. J. Dairy Sci. 80(1):176-186.

Goff J.P. \& Horst R.L. 1997b. Physiological changes at parturition and their relationship to metabolic disorders. J. Dairy Sci. 80(7):1260-1267.

Goff J.P. \& Horst R.L. 1998. Use of hydrochloric acid as a source of anions for prevention of milk fever. J. Dairy Sci. 81:2874-2880.

Goff J.P. \& Kimura K. 2009. Interação entre doenças metabólicas e o sistema imune. Anais $13^{\circ}$ Curso novos enfoques na produção e reprodução de bovinos, Uberlândia, MG, p.251-260.

Gonçalves D. \& Kozicki L.E. 1997. Perfis bioquímicos e imunológicos no período peripartal de vacas leiteiras com e sem retenção de placenta. Braz. J. Vet. Res. Anim. Sci. 34(6):364-370.

Grum D.E., Drackley J.K., Younker R.S., LaCount D.W. \& Veenhuizen J.J. 1996. Nutrition during the dry period and hepatic lipid metabolism of periparturient dairy cows. J. Dairy Sci. 79:1850-1864.

Grummer R.R. 1995. Impact of changes organic nutrient metabolism on feeding the transition dairy cow. J. Dairy Sci. 73:2820-2833.

Guretzky N.A.J., Carlson D.B., Garrett J.E. \& Drackley J.K. 2006. Lipid metabolite profiles and milk production for holstein and jersey cows fed rumen-protected choline during the periparturient period. J. Dairy Sci. 89:188-200.

Kaneene J.B., Miller R., Herdt T.H. \& Gardiner J.C. 1997. The association of serum non esterified fatty acids and cholesterol, management and feeding practices with peripartum disease in dairy cows. Prev. Vet. Med. 31:59-72.

Kaneko J.J., Harvey J.W. \& Bruss M.L. 2008. Clinical Biochemistry of Domestic Animal. 6aㅡ. ed. Elsevier, San Diego. 918p.

LeBlanc S.J. 2010. Health in the transition period and reproductive performance. WCDS Adv. Dairy Technol. 22:97-110.

LeBlanc S.J., Leslie K.E. \& Duffield T.F. 2005. Metabolic predictors of displaced abomasum in dairy cattle. J. Dairy Sci. 88:159-170.

LeBlanc S.J., Lissemore K.D., Kelton D.F., Duffield T.F. \& Leslie K.E. 2006. Major advances in disease prevention in dairy cattle. J. Dairy Sci. 89(4): 1267-1279.

Li P., Li X.B., Fu S.X., Wu C.C., Wang X.X., Yu G.J., Long M., Wang Z. \& Liu G.W. 2012. Alterations of fatty acid $\beta$-oxidation capability in the liver of ketotic cows. J. Dairy Sci. 95:1759-1766.

Lien T.F., Chang L.B., Horng Y.M. \& Wu C.P. 2010. Effects of propylene glycol on milk production, serum metabolites and reproductive performance during the transition period of dairy cows asian-aust. J. Anim. Sci. 23(3):372-378.

Margolles E. 1983. Metabólitos sanguíneos en vacas altas productoras durante la gestación-lactancia en la condiciones de Cuba y su relación com transtornes del metabolismo. Revta Cub. Cienc. Vet. 14:221-230.

Marquardt J.P., Horst R.L. \& Jorgensen N.A. 1976. Effect of parity on dry matter intake at parturition in dairy cattle. J. Dairy Sci. 60(6):929-934.

Moorby J.M., Dewhurst R.J., Tweed J.K., Dhanoa M.S. \& Beck N.F. 2000. Effects of altering the energy and protein supply to dairy cows during the dry period. 2. Metabolic and hormonal responses. J. Dairy Sci. 83:17951805.

Moraes M.P., Weiblen R., Silva A.M. \& Tobias F.L. 1997. Evolução da imunidade passiva em fêmeas bovinas da raça Holandesa. Ciência Rural 27:435-440.

Moreira T.F. 2013. Perfil metabólico de vacas leiteiras no período de transição em sistema semi-intensivo em Minas Gerais no verão e no inverno. Dissertação de Mestrado, Universidade Federal de Minas Gerais, Belo Horizonte. 122p.

National Research Council. 2001. Nutritional Requirements of Dairy Cattle. National Academy Press, Washington DC. 370p.

Oetzel G.R. 2004. Monitoring and testing dairy herds for metabolic diseases. Vet. Clin. Food Anim. Pract. 20:651-674.
Oetzel G.R. 2010. Evaluation of the hand-held Precision Xtra system for diagnosting ketosis in early lactation dairy cows. J. Anim. Sci. 88:526.

OetzeL G.R. \& McGuirk S. 2007. Cow side blood BHBA testing with a handheld "ketometer" fact sheet. School of Veterinary Medicine, University of Wisconsin-Madison.

Ospina P.A., Nydam D.V., Stokol T. \& Overton T.R. 2010a. Evaluation of nonesterified fatty acids and beta-hydroxybutyrate in transition dairy cattle in the northeast United States: Critical thresholds for prediction of clinical diseases. J. Dairy Sci. 93:546-554.

Ospina P.A., Nydam D.V., Stokol T. \& Overton T.R. 2010b. Associations of elevated nonesterified fatty acids and $\beta$-hydroxybutyrate concentrations with early lactation reproductive performance and milk production in transition dairy cattle in the northeastern United States. J. Dairy Sci. 93:3596-3603.

Park A.F., Shirley J.E., Titgemeyer E.C., Cochran R.C., DeFrain J.M., Wickersham E.E. \& Johnson D.E. 2010. Characterization of plasma metabolites in holstein dairy cows during periparturient period. J. Dairy Sci. 5(4):253-263.

Pogliani F.C. \& Birgel Junior E. 2007. Valores de referência do lipidograma de bovinos da raça holandesa, criados no estado de São Paulo. Braz. J. Vet. Res. Anim. Sci. 44(5):373-383.

Reinhardt T.A., Horst R.L. \& Goff J.P. 1988. Calcium, phosphorus and magnesium homeostasis in ruminants. Vet. Clin. North Am., Food Anim. Pract. 4(2):331-350.

Reynolds C.K., Aikman P.C., Lupoli B., Humphries D.J. \& Beever D.E. 2003. Splanchnic metabolism of dairy cows during the transition from late gestation through early lactation. J. Dairy Sci. 86:1201-1217.

Roberts T., Chapinal N., LeBlanc S.J., Kelton D.F., Dubuc J. \& Duffield T.F. 2012. Metabolic parameters in transition cows as indicators for earlylactation culling risk. J. Dairy Sci. 95(6):3057-3063.

Roche J.R., Friggens N.C. \& Kay J.K. 2009. Berry Invited review: Body condition score and its association with dairy cow productivity, health, and welfare. J. Dairy Sci. 92:5769-5801.

Schwalm J.W. \& Schultz L.H. 1976. Relationship of insulin concentration to bloodmetabolites in the dairy cow. J. Dairy Sci. 59(2):255-261.

Seifter S. \& Englard S. 1994. Energy metabolism, p. 323-364. In: Arias I.M. \& Boyler J.L. (Eds), The Liver: biology and pathology. 3rd ed, Raven Press Ltd, New York.

Smith B.P. 2006. Medicina Interna de Grandes Animais. $3^{\text {a }}$ ed. Manole, Barueri. $1784 \mathrm{p}$.

Souza Júnior J.A. 2008. Influência da adição de monensina e propilenoglicol na dieta do periparto de vacas leiteiras sobre o comportamento das concentrações de cálcio, fósforo, magnésio, sódio e potássio. Dissertação de Mestrado, Universidade Federal de Minas Gerais, Belo Horizonte. 88p.

Stengärde L., Tråvén M., Emanuelson U., Holtenius K., Hultgren J. \& Niskanen R. 2008. Metabolic profiles in five high-producing Swedish dairy herds with a history of abomasal displacement and ketosis. Acta Vet. Scand. 50(31):1-11.

Stockham S.L. \& Scott M.A. 2008. Fundamental of Veterinary Clinical Pathology. Blackwell, Iowa. 908p.

Thrall M.A., Weiser G., Allison R. \& Campbell T. 2012. Veterinary Hematology and Clinical Chemistry. 2nd ed. Wiley-Blackwell, Iowa. 776p.

Van den Top A.M., Wensing T. \& Beynen A.C. 1995a. Influence of replacement of dietary hay by an isoenergetic amount of a concentrate rich in medium chain triacylglycerols on fat metabolism in goats. J. Anim. Physiol. Anim. Nutr. 73:104-112.

Van den Top A.M., Wensing T., Geelen M.J., Wentink G.H., Van't Klooster A.T. \& Beynen A.C. 1995b. Time trends of plasma lipids and enzymes synthesizing hepatic triacylglycerol during postpartum development of fatty liver in dairy cows. J. Dairy Sci. 78:2208-2220.

Van den Top A.M., Geelen M.J., Wensing T., Wentink G.H., Van't Klooster A.T. \& Beynen A.C. 1996. Higher postpartum hepatic triacylglycerol concentrations in dairy cows with free rather than restricted access to feed during the dry period are associated with lower activities of hepatic glycerolphosphate acyl- transferase. J. Nutr. 126:76-85. 
Van Dorland H.A., Richter S., Morel I., Doherr M.G., Castro N. \& Bruckmaier R.M. 2009. Variation in hepatic regulation of metabolism during the dry period and in early lactation in dairy cows. J. Dairy Sci. 92:1924-1940.

Vazquez-Añon M., Bertics S., Luck M., Grummer R.R. \& Pinheiro J. 1994. Peripartum liver triglyceride and plasma metabolites in dairy cows. J. Dairy Sci. 77:1521-1528.

Wilson G.D.A., Hunter J.T., Derrick G.H., Aitken W.M. \& Kronfeld D.S. 1977. Fetal and maternal mineral concentrations in dairy cattle during late pregnancy. J. Dairy Sci. 60(6):935-941.
Wittiwer F. 2000a. Diagnóstico dos desequilíbrios metabólicos de energia em rebanhos bovinos, p.9-22. In: González F.H.D., Ospina H., Barcellos J.O. \& Ribeiro L.A.O. (Eds), Perfil Metabólico em Ruminantes: seu uso em nutrição e doenças nutricionais. Gráfica da UFRGS, Porto Alegre.

Wittiwer F. 2000b. Marcadores bioquímicos no controle de problemas metabólicos nutricionais em gado de leite, p.53-62. In: González F.H.D., Ospina H., Barcellos J.O. \& Ribeiro L.A.O. (Eds), Perfil Metabólico em Ruminantes: seu uso em nutrição e doenças nutricionais. Gráfica da UFRGS, Porto Alegre. 